\title{
Socio-economic analysis of the risk management of hexabromocyclododecane (HBCD) in China in the context of the Stockholm Convention
}

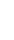

(1)

(1)

(1)

Abstract: Socio-economic analysis (SEA) plays an important role in decision-making on risk management actions for certain chemicals under Multilateral Environmental Agreements (MEAs) in developing countries. This paper showed the first quantitative SEA case study on that. The use of HBCD is being targeted to be phased out in China following the Stockholm Convention on Persistent Organic Pollutants (POPs). Using a systematic approach according to the most possible control scenarios, the study indicates that from 2015 to 2024, the economic costs of HBCD phase-out in China would be between 9.032-19.021 billion RMB. Although the total economic costs is significant, it would only have a marginal impact on the house building industry with a likely cost increase by about $0.07 \%$ - $0.14 \%$ due to the phase-out. Meanwhile, the phase-out may render significant environmental and health benefits. The estimated environmental benefits include about 23-29 tons of HBCD release prevented, 1.142-1.469 million tons of potentially HBCD contained hazardous wastes avoided, along with significant reduction from 58\% up to almost $100 \%$ in local environmental concentrations of HBCD depending on different control scenarios. The health benefits from these actions would include 0.0996-0.128 million workers at risk avoided and at least 3.067-4.033 billion RMB of the health care savings. In conclusion, while the scenario of phasing out HBCD over 10 years would result in higher cost effectiveness than the scenario of that over 5 years in China, the later scenario suggested much greater environmental and health benefits for China.

\footnotetext{
${ }^{1}$ Corresponding author. Tel.:+86 13671204091; E-mail address: jgliu@pku.edu.cn
} 
Keywords: Socio-economic analysis; Risk management of chemicals; Hexabromocyclododecane; Stockholm Convention; China

\section{Introduction}

Although socio-economic analysis (SEA) had become a necessary approach to decision-making of a particular risk management action for certain chemicals, approaches to SEA vary in different countries (OECD, 2000a). In China and most other developing countries, especially since they join the Stockholm Convention on POPs, SEA begun to play more and more important role in the implementation of MEAs for the phase-out of certain hazardous chemicals for environmental protection. This is because for many POPs or other chemicals proven to be potentially toxic to human health and ecosystem, risk management actions could bring about both social \& economic impacts and health \& environmental benefits for local or national community (UNEP, 2007). Then, a holistic SEA that considers all these impacts and benefits of chemicals risk management actions is needed to produce balanced or more comprehensive decision-making reference, especially for developing counties like China.

In this study, a holistic SEA was conducted in China for the risk management of HBCD, a globally important chemical, under the scenario of China implementing the Stockholm Convention. In May 2013, HBCD was listed in Annex A of the Stockholm Convention on Persistent Organic Pollutants (POPs) due to its environmental persistence, bioaccumulation, potential for long-range environmental transport, and likelihood to have significant adverse human health and environmental effects. The implication of the listing is that the production and use of HBCD should be phased out globally (COP.6, 2013b). However, China is the biggest producer and user of HBCD in the world. The annual production of HBCD in China was about 18,000 tons in 2010, accounting for over $60 \%$ of global output (BIT, unpublished results; POPRC, 2011). Over the past decade, the production and use of $\mathrm{HBCD}$ has kept increasing due to the growing market demand for a flame-retardant expanded polystyrene foam (EPS) and extruded polystyrene foam (XPS) using in 
house building industry, which are almost exclusively use of HBCD in China. Moreover, the trend of increasing demand of HBCD is believed to continue into the next decade because of the new national policies and regulations on energy saving and fire protection of the buildings, such as Long-term energy saving special planning, the regulations for the civil building energy efficiency, and The National Norm of Building Fire System Design (GB50016-2014), etc., which will promote the use of EPS and XPS with fire retardant HBCD in China. Therefore, it is predicted that the HBCD phase out will bring about considerable social and economic impacts in China.

\section{Methodology}

\subsection{Scope and indicators}

So far, there is no unified definition of SEA in chemicals risk management. OECD describes SEA in chemicals management as "one of the tools most commonly used in determining whether a risk management measure is justified" (OECD,2000a), as well as the socio-economic impacts that includes compliance costs, human health benefits, environmental benefits and equity considerations (OECD,2002). While the European Chemicals Agency (ECHA) defines SEA as "an approach to analyze all relevant impacts (i.e., both negative and positive changes) in one scenario against another. Relevant impacts include human health, environmental, economic, social, as well as wider economic ones" (ECHA, 2008).

As a result, the approaches to SEA in chemicals risk management varies by country and tend to be on a case-by-case basis according to available SEA cases for chemical risk management (OECD, 2000a; ECHA, 2011a; ECHA, 2011b; ECHA, 2011c; ECHA, 2011d; ECHA, 2012a; ECHA, 2012b; ECHA, 2012c; EPA, 2013). The study adopts the ECHA definition and develops a country specific SEA framework based on real national situations related to HBCD control under the Convention implementation scenario for China. The scope and indicators of SEA in this study are as follows:

\section{a. The gross economic costs (GECs)}


GECs here refer to the net costs to society for a contracting party as a whole caused by performing the international conventions' chemicals control objectives, which comprise the economic loss of chemicals to the manufacturing sector (MSL), i.e. economic losses to chemical production and processing industry; the substitution costs of chemicals'use sector (USCs), and the supervision cost of the government (SCs). Therefore, the assessment indicators of GECs in this study include the economic losses to manufacturers of HBCD and the manufacturers of EPS and XPS containing HBCD (i.e. the processers of HBCD); the additional costs caused by the application of alternatives to HBCD in building materials; and the government supervision costs caused by implementing the convention.

\section{b. Social impacts (SIs)}

SIs here include all relevant impacts which may affect workers, consumers and the general public that are not covered under economic, health, or environmental impacts, such as employment, working conditions, job satisfaction, education of workers and social security (ECHA, 2008). The SEA adopted the quantifiable employment impacts (EIs) as the assessment indicator for social impacts.

\section{c. Environmental benefits (EBs)}

EBs here refer to the environmental quality improvement and/or environmental risk reduction due to chemicals risk management. Those environmental benefits are usually difficult to be quantified or further monetized. Obviously, reducing and eventually eliminating the release of HBCD will contribute to environmental protection. According to the properties and methods of chemical risk management and data availability, this study adopted three indicators for environmental benefits assessment, including the reduction of HBCD release (RR), the reduction of the amount of related potentially hazardous waste (RW), and the reduction of the environmental concentration and risk of HBCD (RC\&R).

\section{d. Health benefits (HBs)}

HBs here refer to the occupational and public health benefits due to chemicals risk management. 
Similar to EB assessment, HBs is usually also difficult to be quantified or monetized. According to available risk assessments of $\mathrm{HBCD}$, the human health risks of $\mathrm{HBCD}$ is mainly due to occupational exposure (Swedish Chemicals Agency, 2008), while the risks from public exposure could be ignored since the environmental concentration of $\mathrm{HBCD}$ is normally very low. Given the HBCD phase-out will mainly lead to a decrease in occupational exposure (through inhalation and derma uptake) in the country, the reduced number of workers under the occupational health risks of HBCD and the associate cost saving of treating the possible disease caused by HBCD were used as the indicator of the HBs.

\subsection{Scenario analysis}

It is generally predicted that China will ratify the new amendment of Stockholm Convention including HBCD as early as 2015. According to specific exemption articles on HBCD in the Convention, China could have either a 5-year or a 10-year specific exemption on the production and use of HBCD in EPS/XPS (Stockholm Convention, 2012). Therefore, 2014 has been set as the base year, 2019 and 2024 have been set as the two timelines of control scenarios corresponding to 5-year and 10-year of possible specific exemption period of production and use of HBCD in China.

\subsubsection{Baseline scenario analysis}

As mentioned before, without the convention for compliance, the production and use of HBCD in China would keep increasing due to the demand of the flame-retardant EPS and XPS for building construction. The baseline scenario analysis takes into account three key factors, i.e., economic growth, policies on firefighting and energy saving for buildings and alternative technologies to predict the demand of the flame-retardant EPS and XPS, and then that of HBCD in the next decade.

i. Economic growth. Based on the statistical data from China Statistics Book (China Statistics Book, 2007-2013) and China Plastics Processing Industry Association (CPPIA), there was a strong linear relationship between the floor space of buildings completed (including new and renovated buildings) and both the constant-price GDP and the EPS/XPS output, which was shown in Fig. 1. An average annual growth rate at 7\% for the constant-price GDP was used to predict the output of 
EPS/XPS, according to "The outline of the 12th five-year plan for economic and social development of People's Republic of China" (from 2011 to 2015) (NDRC, 2011). Accordingly, the output of HBCD in the next decade can be predicted based on the weighted proportions of HBCD in EPS and XPS foams in China.
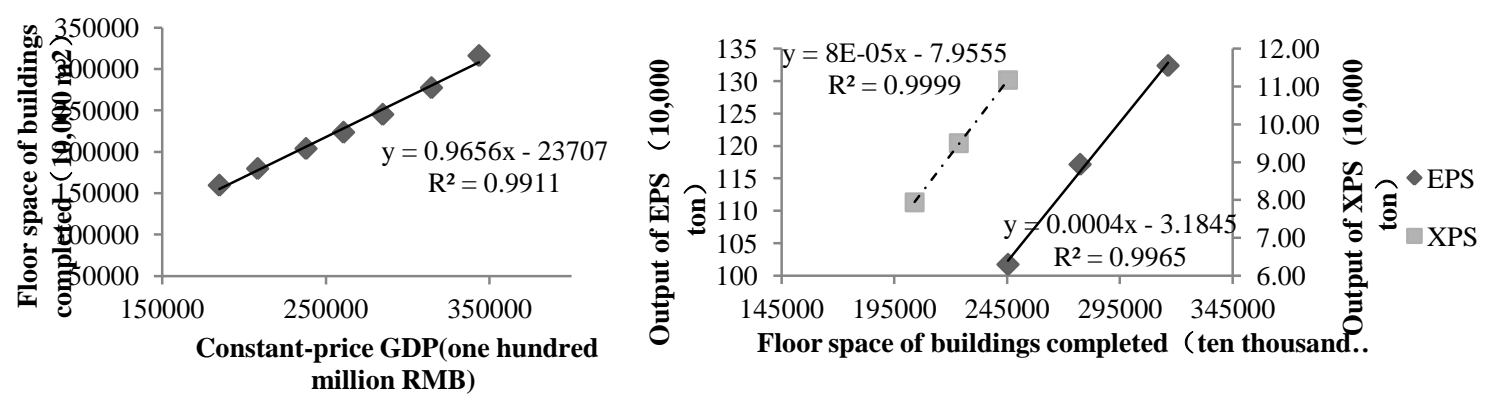

Fig. 1. Relationships between the floor space of completed buildings and the constant-price GDP, and EPS/XPS output

\section{ii. Policies on energy saving and firefighting for buildings. In China, building energy} efficiency requirements have been increasingly improved by laws and regulations such as the Long-term Energy Saving Special Planning (2004), and Energy Conservation Law of the People's Republic of China (Presidential Decree No. 77, 2008). Because the exterior wall thermal insulation system has become common in the house building sector in China, it is anticipated that the market demand for EPS/XPS will increase to meet the requirements of energy conservation building policies and increasing consumer demand for a controlled indoor thermal environment.

Meanwhile, increasing attention is being paid to the fire performance requirements of exterior insulation materials in buildings in China. The Fire Prevention Regulations for Civil Building Exterior Thermal Insulation Systems and Exterior Wall Decoration (2009) has enhanced the requirements for the combustion performance of external wall thermal insulation materials for civil buildings, while the National Norm of Building Fire System Design (GB50016) emphasizes the requirement for insulation flame retardant materials for non-civic buildings and improved fire-protection rating requirements. The energy conservation and fire safety policies for buildings in 
China will not only promote the market of insulation building materials but also affect the market shares of insulation materials at different fire ratings.

iii. Alternative technology. The recognition of $\mathrm{HBCD}$ as a POP and its listing in the Stockholm Convention are stimulating the market development of alternative flame retardants without HBCD both domestically and internationally, even without the coercive elimination of HBCD. Currently, the market shares of EPS/XPS, polyurethane (PU), and other thermal insulation materials are approximately $80 \%, 10 \%$ and $10 \%$ respectively in China(Huang, 2009). In comparison, PU accounts for nearly $50 \%$ of the market of Europe and North America(Huang, 2009), and the EPS industry holds a market share of $35 \%$ of the total insulation market for construction in Europe (EUMEPS-European Association of EPS, 2015). Although EPS/XPS materials have advantages over PU in terms of much lower price and the maturity of both technology and market in China, PU also has several advantages including lower heat conductivity, higher density, and better infiltration effects (Liu and Bai, 2003; Al-Homoud, 2005). Therefore, the market share of PU is predicted to increase gradually in future in China, even without the HBCD restriction. It was also assumed that the market share of EPS/ XPS foams would decrease linearly from $80 \%$ in 2014 to $60 \%$ in 2024, while at the same time, the market share of PU and other HBCD-free thermal isolation building materials would increase linearly from $10 \%$ in 2014 to $20 \%$ in 2024 respectively.

\subsubsection{Control scenario analysis}

According to an international review on alternative technologies to HBCD conducted by POPRC and relevant national situation of China in relation to flame retardant substitution and resin/material substitution, there could be two major alternative technical solutions for phasing out HBCD in China to implement the Convention (POPRC, 2011). For flame retardant substitution, a brominated co-polymer of styrene and butadiene named Emerald 3000 (EM 3000) is deemed as one of the most likely alternative flame retardants of HBCD used in EPS/XPS in the future (POPRC, 2012). For resin/material substitution, PU will probably be the most likely alternative building insulation material as mentioned previously. Though the substitution of HBCD for construction purposes may also be aided by product redesign, such as technical solutions and changes in construction practices 
such as using fire barrier materials to separate the source of heat from the building materials (POPRC, 2011), it is difficult to promote such substitution in China given that specific fireproof performance for thermal insulation materials is required by current building fire safety regulations .

Therefore, the market demand for EPS/XPS containing HBCD will gradually decrease to zero due to the obligations of the Convention by the control scenario year at 2019 or 2024 . The use of alternative insulation materials will gradually increase. Although the market share of EPS/XPS will decrease, they could still be the dominant insulation materials used in house building industry of China because of their both technical and cost-benefit advantages in thermal insulation materials for buildings, as long as they uptake the alternative flame retardants. It was assumed that the output of HBCD would decrease linearly until it was completely eliminated. In the 5-year or 10-year phase-out scenario, the market share of PU would experience $10 \%$ of additional linear growth over the baseline scenario from 2014 to 2020 or 2025 of the control scenario, respectively. The market share of EPS/ XPS would decrease proportionally from $80 \%$ in 2014 to $50 \%$ in 2020 or 2025, respectively, and it then would remain at 50\%, and EM 3000 would be the alternative flame retardant used in them instead of HBCD.

\section{Based on such a scenario analysis, the trends of the outputs of HBCD and market shares of EPS in} the 2019 and 2024 were predicted as shown in Fig.2 (The trend for XPS was same as EPS in both the baseline and control scenario). The database of the scenario analysis is shown in Table S1.
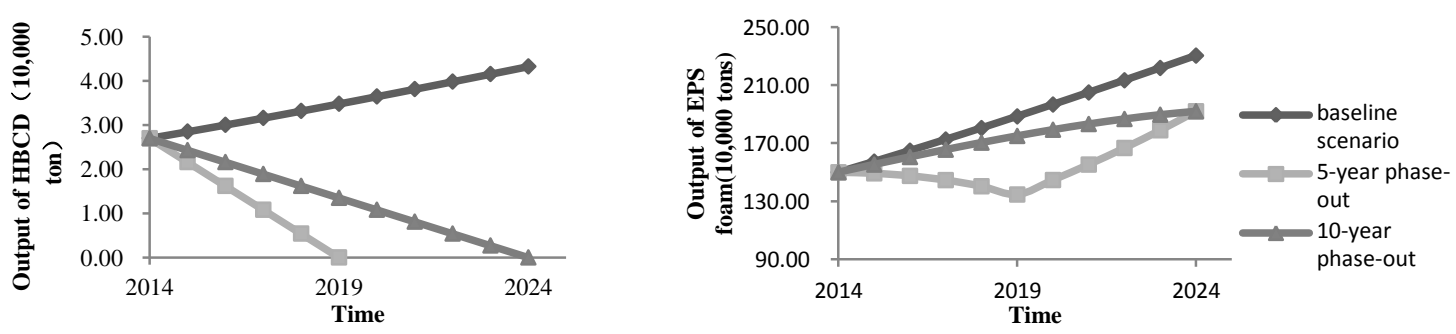

Fig.2. The trends of variation in the outputs of HBCD and EPS foams 


\subsubsection{Economic loss of the manufacture sector (MEL)}

The MEL consists of losses from both domestic and export sales. In terms of the costs to society as a whole, if there was a corresponding industrial production and use chain for a domestic substitute, the domestic profits could simply be redistributed rather than being lost to the domestic economy (ECHA, 2008a). With the use of HBCD restricted, EM 3000 will be imported into China, while the domestic PU resin and PU insulation board production capacity could meet the market demand, according to the Twelfth Five-Year development planning proposals of the PU industry of China (CPUIA, 2011). Therefore, the loss of profits from domestic sales included only sales of HBCD, and the loss of profits from export sales included sales of HBCD. The loss of sales profits was estimated using:

$$
\mathrm{MEL}_{e}=\sum_{i=1}^{t} \Delta Q_{\mathrm{ei}} \times P_{0} /(1+\mathrm{r})^{i}
$$

where $\mathrm{MEL}_{e}$ is the accumulated loss of sales profits over $t$ years, $\Delta \mathrm{Q}_{\mathrm{ei}}$ is the reduced sales in the $i$ th year, $P_{0}$ is the unit sales profit, $i$ is the year, and $r$ is the discount rate (5\% in this study).

\subsubsection{Substitution costs of the use sector (USCs)}

USCs are affected by the price of the original and alternative products, as well as the amount of substitution. It is difficult to predict the prices of HBCD, EPS/XPS, and PU due to complicating factors such as the price of raw materials, and supply and demand issues. The study assumes that the prices of HBCD, EPS/XPS, and PU remained unchanged during the time frame of the analysis.

The price of EM 3000 is probably 15-120\% higher compared with HBCD according to (POPRC, 2012) and from consultation with experts. Considering that EM3000 will be phased in as a new product, the trend in its price should comply with the rules of a product life cycle and should therefore gradually decline to the market equilibrium price (Dean, 1950; Levitt, 1965). In this study, the price of EM 3000 was assumed to be $50 \%$ higher than the price of HBCD in 2015 and would 
decrease linearly until 2019 when it would be the same price as HBCD. The replacement costs were estimated using:

$$
\mathrm{USCs}=\sum_{i=1}^{t}\left(\Delta Q_{i} \times C s i-\Delta Q_{i}{ }^{\prime} \times C_{0}\right) /(1+\mathrm{r})^{i}
$$

where USCs is the total replacement cost in use sector, $\Delta Q_{i}$ is the additional amount of alternatives required to achieve the same flame retardant efficiency or heat preservation effect, $C s i$ is the price of alternatives in the $i$ th year, $\Delta Q_{i}{ }^{\prime}$ is the reduced amount of the original products, and $C_{0}$ is the price of alternatives.

\subsubsection{Supervision cost of the government (SCs)}

According to China's chemicals management policy, the management costs of phasing out HBCD will mainly include the costs of the establishment of environmental management measures for HBCD, enforcement and supervision on manufacturers and processors of HBCD, environmental pollution and occupational health effects monitoring of $\mathrm{HBCD}$, general environmental monitoring of HBCD for effectiveness evaluation, and relevant training programs. In this study, we assume that all the supervision activities and relevant training programs would be undertaken at each of the six major region where production and processing mainly occur, covering all enterprises producing or processing HBCD, EPS beads, and XPS foams that have direct contact with pure HBCD. The detailed methods of the SCs estimation were descripted in Text Section 1 of the supporting information.

\subsection{Social impact (SI) analysis}

There are 14 manufacturers of HBCD (BIT. unpublished results), 25 manufacturers of EPS beads and about 500 manufacturers of XPS foam in China (Wang, Y., 2010). The study adopts the maximum quantity in the field survey data, 50 workers per factory, to estimate the number of workers in the above factories. There are about 10 thousand EPS foam manufacturers in China

${ }^{2}$. Since not all workers in those factories come into direct contact with pure HBCD, it was predicted

\footnotetext{
${ }^{2} 2011$ China industry peak forum
} 
that there are about 20 relevant workers per factory according to our onsite survey on certain EPS producers. Then, a total employment of 0.227 million in this sector is estimated. We compare the possible rate of unemployment to relevant indicator in China to judge the impact. Furthermore, we analyze the EIs on different steps on the HBCD life cycle to identify the main affected industries.

\subsection{Environmental benefits (EBs) analysis}

\subsubsection{The reduction of $H B C D$ release $(R R)$}

The release of HBCD that would be avoided during the first three life cycle steps (production, processing and industrial use of $\mathrm{HBCD}$ ) is estimated using:

$$
\mathrm{RR}=\sum_{\mathrm{i}=1}^{\mathrm{t}}\left(\Delta \mathrm{Q}_{\mathrm{pi}} \times \mathrm{q} 1+\Delta \mathrm{Q}_{\mathrm{mi}} \times \mathrm{q} 2\right)
$$

where RR is the total cut in release of HBCD from 2015 to $2024 ; \Delta Q_{\mathrm{pi}}$ is the cut in output in the $i$ th year; $\Delta Q_{\mathrm{mi}}$ is the volume reduced from processing and industrial use in the $i$ th year (i.e., domestic sales volume), $q 1$ is the total emission factor for air and water during production, $q 2$ is the total emission factor during processing and industrial use. We adopted the measured emission factors provided in (Swedish Chemicals Agency, 2008) which were more precise according to the Technical Guidance Document on Risk Assessment (TGD) (ECB, 2003), i.e., $q 1$ was set at $4.55 \times 10^{-7}$, and $q 2$ at $1.43 \times 10^{-4}$. Because it was assumed that all XPS foams were made from XPS polymer but not from pure HBCD, the release cuts calculated here would be an overestimated as there would be additional emissions of HBCD during the process of forming XPS compounds.

\subsubsection{The reduction in the amount of related potentially hazardous waste $(\mathbf{R W})$}

The reduction in the amount of potentially hazardous waste (i.e., EPS/XPS) is estimated using:

$$
R W=\sum_{i=1}^{t}\left(Q_{i}-Q_{i}{ }^{\prime}\right)
$$

where RW is the total reduction in EPS/XPS from 2015 to $2024, Q_{i}$ and $Q_{i}{ }^{\prime}$ are the amounts of EPS/XPS containing HBCD used in the baseline and control scenarios, respectively. 
The preliminary simulation assessment of HBCD environmental risk involves all the regions in China. This study assesses the environmental benefits in 5-year and 10-year phase out scenario at 2019 and 2024 from three aspects: the reduction of average concentration of HBCD at national level; the reduction of concentration of $\mathrm{HBCD}$ in Eastern China with greatest risk at regional level; the reduction of concentration and risk of $\mathrm{HBCD}$ in Eastern China at local level ${ }^{3}$. Soil and sediment are chosen to be the assessed media as the main environmental fate of HBCD. For such a purpose, the regional Predicted Environmental Concentrations (PECs) of HBCD in seven regions of China and local PECs in Huadong region in 2014, 2019 and 2024 both under the baseline scenario and control scenarios are simulated by localized application of EUSES 2.1.2. The detail description on the EUSES model and the simulation outputs (regional PECs of HBCD in China) can be found in Text Section 2 of supporting information.

\subsection{Health benefits (HBs) analysis}

The occupational exposure and the accompanying health risk of HBCD occur mainly in the process of loading and unloading of HBCD in production and processing (Swedish Chemicals Agency, 2008). Exposure and risk depends on several factors such as chemicals properties, environmental conditions, pattern of use, patter of control applied to the process, frequency of contact and exposed body part. Under the same working conditions, the occupational exposure and risks of HBCD are associated with the volume of the production and processing. This study first uses the EASE model to simulate the occupational health risk in different exposure scenarios, then predicts the number of workers at risk in the specific scenario, and further adopts the disease cost method to preliminarily monetize the occupational health benefit.

EASE (Estimation and Assessment of Substance Exposure) is a widely used model developed by

\footnotetext{
${ }^{3}$ The preliminary environmental risk assessment of HBCD in this study indicated that as the main area of production and use of HBCD, Eastern China is of the highest HBCD concentration. And it was the only region with environmental risk of $\mathrm{HBCD}$ in China where high $\mathrm{HBCD}$ local concentration could be higher than the existing risk threshold. See supporting information Section 2.
} 
the UK Health and Safety Executive to model inhalation and dermal workplace exposure across a wide range of circumstances (Institute for health and consumer protection, 2008). The detailed description on the EASE model, calculation process and the simulation outputs can be found in Text Section 3 in the supporting information. Furthermore, quantifying the occupational health benefit is always an advanced research field in SEA in chemicals management. Since there is no available information regarding the dose-effect relationships of $\mathrm{HBCD}$ and its associated human health effects, the study monetizes the occupational health benefits by using the cost-of -illnesses which is based on the available statistic cost data of treating kinds of diseases.

$$
\begin{aligned}
& \text { Benefit }=\sum_{i=1}^{t}\left(N i \times B_{0}\right) /(1+\mathrm{r})^{i} \\
& \mathrm{~B} 0=\mathrm{B} 1+\mathrm{B} 2
\end{aligned}
$$

where Benefit is the total monetized health benefits in control scenarios; $N i$ is the reduced number of workers at risk in the ith year; $B_{0}$ is the health benefits of a year; $\mathrm{B} 1$ is the avoided medical costs; B2 is the avoided loss income due to the time missed from work. The average hospitalization days and medical expense of per disease, and the daily wage of workers that were used for calculating B1 and B2 were from (China Health Statistics Book, 2012) and field research.

\section{Results and Discussion}

\subsection{The economic and social impacts of HBCD phase-out in China}

The GECs of the HBCD phase-out in 2015 or 2024 in China under the two possible scenarios for China are summarized in Table 1. As shown in Table 1 and Table 3, the total economic costs in the 5-year and 10-year phase-out scenario were 19.021 and 9.032 billion RMB respectively. The total industrial economic cost in the 5-year phase-out scenario is much higher than that in the 10 -year phase-out scenario. Due to the higher price of PU compared with EPS/XPS and the large amounts required for replacement, the cost of replacing insulation materials accounts for about $80 \%$ of the industrial economic cost, which is dominated by the replacement costs of EPS. However, the requirements for more frequent supervision and more items during the 10-year phase-out scenario generates higher management costs than in the 5-year phase-out scenario. The higher management 
costs in the 10-year phase-out scenario is largely contributed by the higher costs of managing environmental pollution and occupational health effects, and monitoring of HBCD and relevant personal training programs.

The SIs of the HBCD phase-out would be small. Even if all of the 0.227 million employees of the HBCD industry chain were laid off, the urban unemployment rate would increase from $4.1 \%$ to $4.7 \%$ based on the statistical data of the total urban unemployment rate in China in 2012. This is still well below the maximum acceptable urban unemployment rate of 7\%. Phasing-out HBCD in 5 or 10 years would also provide some buffer time to find a new job. Since HBCD accounts for nearly $100 \%$ product share in $85 \%$ manufacturing enterprises (BIT, unpublished results), phasing out HBCD may have a larger employment impact in this sector. However, the production transfer to alternative flame retardants being undertaken by HBCD manufacturers in China would alleviate the impact on employment to some extent. Since the property similarity between HBCD and the selected alternative flame retardants, the technology transformation cost of using the alternative to produce EPS beads and XPS masterbatch would be small.

\subsection{Environmental and Health benefits}

For China, the SEA clearly indicates that the HBCD phase-out could bring significant environmental benefits, and that benefits under 5-year phase-out scenario would be much more significant than that under the 10-year scenario. As shown in Table 2, the reduction in the release of HBCD and in the amount of potentially hazardous waste in the 5-year phase-out scenario would be larger than that in the 10-year phase-out scenario. In the 5-year phase-out scenario, 29 tons of HBCD release would be prevented, 1.142 million tons of potentially hazardous wastes containing HBCD would be avoided. Whereas in the 10-year phase-out scenario, 23 tons of HBCD release would be prevented, 1.469 million tons of potentially hazardous wastes containing HBCD would be avoided.

In China, according to the simulation on regional environmental concentrations of HBCD by using EUSES (Figure 3), the highest PECs of HBCD would occur in East China. Taking for example the 
HBCD concentrations in the sediment at local level in East China.as shown in Figure 4, a HBCD

362

363 was no HBCD risk. phase-out action could significantly reduce the environmental concentrations of HBCD, and the associated environmental risk. By 2019, the local HBCD environmental concentrations could fall 95\% percent and 58\% percent in the 5-year and 10-year phase-out scenario respectively from the baseline scenario. By 2024, the HBCD environmental concentrations could decline $99.99 \%$ and $98 \%$ under the 5-year and 10-year phase-out scenario respectively from the concentration found under the baseline scenario. From 2014 to 2019, the environmental risk level (RCR value) in the local sediment environment in East China would decline from 52 in the baseline scenario to 2.8 and 2.2 under the 5-year and 10-year phase-out scenario respectively. By 2024, that risk level would decline from 64 in the baseline scenario to 1.5 under 10-year phase-out scenario. This was close to the risk threshold. The risk level would drop to 0.0035 under 5-year phase-out scenario, which meant there

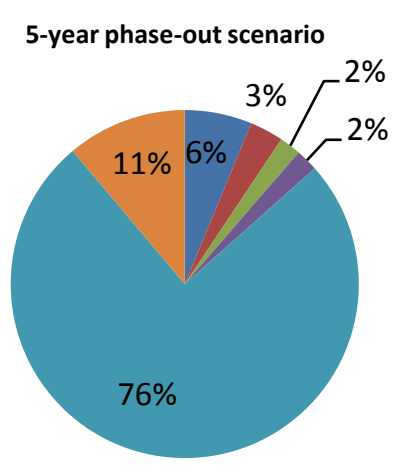

373

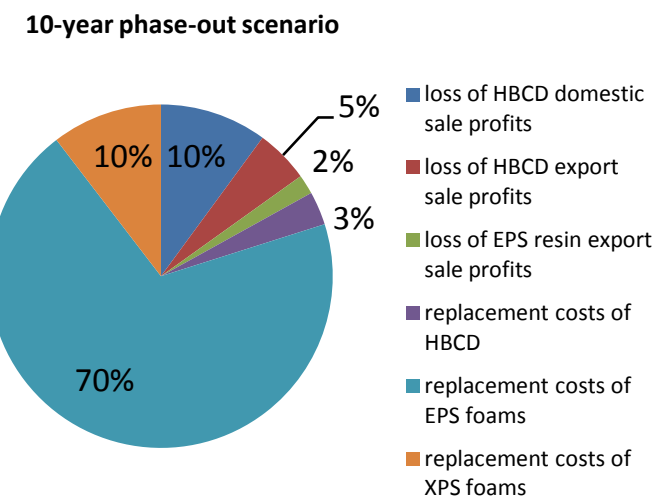

Fig.3. Proportions of industrial economic costs

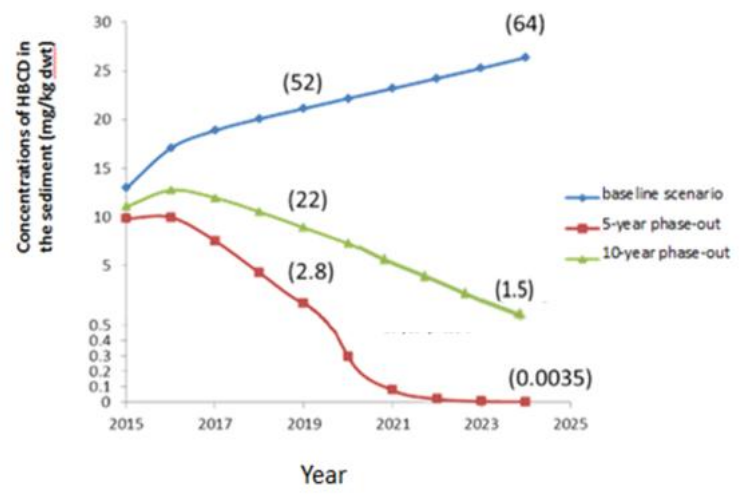

Fig.4. Concentrations and risks of $\mathrm{HBCD}$ in sentiment in East China at local level in different 
379 The health benefits of HBCD phase-out under both the 5-year and 10-year scenario would be significant; with the 5-year scenario being better than the10-year scenario. The health risk assessment using EASE model (see Section 3 of SI for detail) indicates that there was a health risk for all workers in the HBCD handling unit in its manufacturing, formulation and processing plants under the worst exposure scenario. Based on both the statistical and onsite survey of HBCD manufacturers and processors of China, from 2015 to 2024 the predicted number of workers at risk would reduce by 12.8 ten thousand and 9.96 ten thousand under the 5-year and 10-year phase-out scenario respectively. According to the disease cost method, the corresponding monetized health benefits were calculated at about 4.033 billion RMB and 3.067 billion RMB respectively.

\subsection{Comprehensive analysis}

Therefore, phasing out HBCD over 10 years would result in less costs and higher cost effective than phasing out over 5 years. As shown in Table 3, the total costs and net costs in the 10-year phase-out scenario were all smaller than the equivalent costs in the 5-year phase-out scenario. Cost per ton of emission reduced and additional cost per floor space of buildings completed in the 10-year phase-out scenario were all smaller than the equivalent costs in the 5-year phase-out scenario.

However, the 5-year phase-out scenario would bring more environmental and health benefits than the 10-year scenario. On avoided HBCD release and potential hazardous wastes, and the reduced number of workers at risk and monetized health benefits. Phasing out HBCD in 5 years could dramatically reduce the $\mathrm{HBCD}$ environmental concentrations and risks. Due to the inherent complexity of ecology and environmental services and lack of relevant data, the environmental benefits are difficult to monetize which could influence the assessed net benefits.

Although the total costs in both control scenarios were high, the additional cost per floor space of buildings completed was less than 0.4 RMB, and the increase in building construction costs ranged from $0.07 \%$ o to $0.14 \%$, which indicates that phasing out HBCD in China would have a limited 
impact on the construction industry.

\section{Conclusions and uncertainties}

407

SEA has increasingly played an important role in the management of chemicals, especially in the implementation of the Stockholm Convention. This study using SEA assesses the impacts of HBCD phase-out in China in the context of the Stockholm Convention. The results showed that phasing out HBCD over 10 years would be more cost effective than doing so over 5 years. From 2015 to 2024, the economic costs ranged from 9.032 to 19.021 billion RMB. The phase-out of HBCD could result in a 23-29 tons reduction in the release of $\mathrm{HBCD}$ and reduce potentially hazardous waste containing HBCD by 11,415-14,689 thousand tons over the 10 years. Furthermore, there would be a significant reduction in HBCD environmental concentration and the risk to 0.0996-0.128 million workers would be avoided on the basis of occupational health risks as assessed by EASE model. The monetized benefits would be at least 3.067-4.033 billion RMB. However, the 5-year phase-out scenario would bring more environmental and health benefits than the 10-year scenario. Further analysis showed that phasing out HBCD would increase construction costs by only $0.07-0.14 \%$, indicating that the economic costs would not be significant in China, whereas the health and environmental benefits could be very significant.

It should be noted that some uncertainties may influence the accuracy of the estimated costs and benefits. For example, one of the main uncertainties in assessing the economic costs is the price and cost of using alternatives to HBCD and EPS/XPS because there are a number of alternatives on the market, and all of their prices fluctuate. Another main uncertainty regards the lack of emission and monitoring data in China which may influence the accuracy of environmental benefit assessment. Lack of information regarding the dose-effect relationships of HBCD and its associated human health effects also create in uncertainty in assessing health benefits. The health benefits calculated using the cost of illness method is usually considered as the lower limit, so the health benefits may have been underestimated ${ }^{4}$.

\footnotetext{
${ }^{4}$ The study suggests that there is still a pressing need to construct an information system for target chemicals
} 
It is worth noting that current available alternative technologies of HBCD would also have negative environmental and health impacts. For example, the flame-retardant PU may uses TRIS (2-CHLORO-1-METHYLETHYL) PHOSPHATE (TCPP) as flame retardant which is classified as potentially carcinogenic, and PU has a higher fire toxicity (Stec AA, Hull TR,2011) . Also brominated polystyrene can result in high fire toxicity due to inhibiting decomposition of carbon monoxide (Molyneux S et al., 2014). These negative effects of the alternatives used should be taken into account in the refined SEA analysis in future.

\section{Acknowledgements}

The study is funded by the Ministry of Environmental Protection of China, with data support from the China Flame Retardant Society (CFRS) and the China Plastics Processing Industry Association, and the support from National Science Foundation of China (No.21206011) and The Importation and Development of High-Caliber Talents Project of Beijing Municipal Institutions of the National Basic Research Program of China (No. IDHT201304084). We thank Professor Li-Jun Qian and Professor Zheng-Mao Zhou of the CFRS for providing extensive technical consultation. Opinions in the paper are those of the authors and not necessarily those of the funding agencies.

\section{References:}

Al-Homoud, M. S., 2005. Performance characteristics and practical applications of common building thermal insulation materials. Building and Environment 40: 353-366.

BIT. Unpublished results. Basic Information Investigation Report for HBCD. Beijing Institute of Technology. (in Chinese)

China Health Statistics Book , 2012. China Union Medical University Press.(in Chinese)

China Real Estate Yearbook, 2013. Tianjin University Press. (in Chinese)

China Statistics Book, 2007-2013.National Bureau of Statistics of China. China Statistics Press, Beijing. (in Chinese)

that includes relevant economic and social data and to undertake studies that monetize health and environmental benefits. 
CIA, 2012. China Real Estate Statistics Yearbook 2012. China Index Academy of National Bureau of Statistics of China. China Statistics Press, Beijing, p. 99. (in Chinese)

COP.6, 2013a. Recommendation by the Persistent Organic Pollutants Review Committee to list hexabromocyclododecane in Annex A to the Stockholm Convention and draft text of the proposed amendment. UNEP/POPS/COP.6/17. UNEP, Conference of the Parties to the Stockholm Convention on Persistent Organic Pollutants, Sixth meeting, Geneva.

COP.6, 2013b. Report of the Conference of the Parties to the Stockholm Convention on Persistent Organic Pollutants on the work of its sixth meeting UNEP/POPS/COP.6/33. UNEP, Conference of the Parties to the Stockholm Convention on Persistent Organic Pollutants, Sixth meeting, Geneva.

CPUIA, 2011. Twelfth Five-Year Development Planning Proposals of the PU Industry of China. China Polyurethane Industry Association.

DEAN J., 1950. Pricing policies for new products. Havard Business Review, 45-53.

Drottar KR, Krueger HO, 1998. Hexabromocyc lododecane (HBCD): a flow-through life-cycle toxicity test with the cladoceran ( Daphnia magna). Final report. 1998; 439A-108, pp 78. Wildlife International, Ltd., Easton, MD, USA.

ECB, 2003. Technical Guidance Document on Risk Assessment: Part II. European Chemicals Bureau, Institute for Health and Consumer Protection. Italy.

ECHA, 2008. Guidance on Socio-economic Analysis-Restrictions. European Chemicals Agency, Helsinki, Finland.

ECHA, 2011a. Background document to the opinions on the Annex XV dossier proposing restrictions on dimethylfumarate (DMFu). European Chemicals Agency, Helsinki, Finland.

ECHA, 2011b. Background document to the opinions on the Annex XV dossier proposing restrictions on mercury in measuring devices. European Chemicals Agency, Helsinki, Finland.

ECHA, 2011c. Background document to the Opinions on the Annex XV dossier proposing restrictions on five phenylmercury compounds. European Chemicals Agency, Helsinki, Finland.

ECHA, 2011d. Background document to the opinions on the Annex XV dossier proposing restrictions on lead and its compounds in jewelry. European Chemicals Agency, Helsinki, Finland.

ECHA, 2012a. Background document to the Opinion on the Annex XV dossier proposing restrictions on four phthalates. European Chemicals Agency, Helsinki, Finland. 
ECHA, 2012b. Background document to the Opinion on the Annex XV dossier proposing restrictions on chromium VI in leather articles. European Chemicals Agency, Helsinki, Finland.

ECHA, 2012c. Background document to the Opinion on the Annex XV dossier proposing restrictions on 1,4-dichlorobenzene. European Chemicals Agency, Helsinki, Finland.

Ema, M., Fujii, S., Hirata-Koizumi, M., Matsumoto, M., 2008. Two-generation reproductive toxicity study of the flame retardant hexabromocyclododecane in rats. Reproductive Toxicology 25: 335-351.

EUMEPS-European Association of EPS.

http://www.eumeps.construction/index.php?id=4105\&psid=iolid9fclbbtvp9aprpfbnllu6. (last accessed Oct 2015)

GEF, 1996. Incremental Costs. GEF/C.7/Inf.5. Global Environmental Facility.

Huang M.S., 2009. Analysis of application in construction insulation materials and fire safety performance of polyurethane. Polyurethane 26-30.

Hou S.T., 2011. The third session of the Standing Committee work report of EPS Special Committee of China Plastics Processing Industry Association. (in Chinese)

Institute for health and consumer protection. EUSES, the European Union System for the Evaluation of Substances, EUSES 2.1.1 User Manual.2008.

Levitt, T., 1965. Exploit the product lifecycle. Havard Business Review 6: 81-94.

Lilienthal, H., van der Ven, L.T.M., Piersma, A. H., Vos, J. G., 2009. Effects of the brominated flame retardant hexabromocyclododecane (HBCD) on dopamine-dependent behavior and brainstem auditory evoked potentials in a one-generation reproduction study in Wistar rats. Toxicology Letters 185: 63-72.

Liu, Y. J., Bai, S., 2003. Flame retardation of polyurethane foams. China Plastics Industry, 1-4+15. (in Chinese)

Molyneux S, Stec AA, Hull TR (2014) The effect of gas phase flame retardants on fire effluent toxicity. Polymer Degradation and Stability106 (2014) 36-46.

NDRC, 2011. Outline of the 12th Five-year Plan for Economic and Social Development of the People's Republic of China. China, National Development and Reform Commission, Beijing.

OECD, 2000a. Guidance for Conducting Retrospective Studies on Socio-economic Analysis. ENV/JM/MONO (99)27. Organization for Economic Co-operation and Development, Paris, France. 
OECD, 2000b. Framework for Integrating Socio-economic Analysis in Chemical Risk Management Decision Making. ENV/JM/MONO (2000)5. Organization for Economic Co-operation and Development, Paris, France.

OECD, 2002. Technical Guidance Document on the Use of Socio-economic Analysis in Chemical Risk Management Decision Making. ENV/JM/MONO (2002)10. Organization for Economic Co-operation and Development, Paris, France.

POPRC, 2011. Risk Management Evaluation on Hexabromocyclododecane. Report of the Persistent Organic Pollutants Review Committee on the work of its seventh meeting: Addendum. UNEP/POPS/POPRC.7/19/Add.1. UNEP, Persistent Organic Pollutants Review Committee, Geneva, Switzerland.

POPRC, 2012. Intersessional Work on Hexabromocyclododecane. UNEP/POPS/POPRC. 8/4. UNEP, Persistent Organic Pollutants Review Committee, Eighth meeting, Geneva, Switzerland.

Ronisz, D., Finne, E F., Karlsson, H., Forlin, L., 2004. Effects of the brominated flame retardants hexabromocyclododecane (HBCDD), and tetrabromobisphenol A (TBBPA), on hepatic enzymes and other biomarkers in juvenile rainbow trout and feral eelpout. Aquatic Toxicology 69: 229-245.

Stec AA, Hull TR, 2011.Assessment of the fire toxicity of building insulation materials. Energy and Buildings, 43 (23), pp. 498-506 doi:10.1016/j.enbuild.2010.10.015.

Stockholm Convention,2012. Recommendation by the Persistent Organic Pollutants Review Committee to list hexabromocyclododecane in Annex A to the Stockholm Convention and draft text of the proposed amendment. UNEP/POPS/COP.6/17. Geneva.

Swedish Chemicals Agency, 2008. Risk Assessment—Hexabromocyclododecane, final report. Swedish Chemicals Agency, Sundbyberg, Sweden.

UNEP, 2007. Draft Guidelines for the Social-economic Assessment involved in Designing and Implementation of the National Implementation Plan of Persistent Organic Pollutants. United Nations Environment Programme, Dakar, Senegal.（in Chinese）

USEIA, 2011. International Energy Outlook 2011. US Energy Information Administration, Washington, DC.

USEPA, 2013. Economic Analysis of the Formaldehyde Standards for Composite Wood Products Act Implementing Regulations Proposed Rule. US Environmental Protection Agency, Washington D.C. 
542 van der Ven, L. T. M., Verhoef, A., van de Kuil, T., Slob, W., Leonards, PEG., Visser, T J., Hamers, T.,

543 Herlin, M., Hakansson, H., Olausson, H., Piersma, A. H., Vos, J. G., 2006. A 28-day oral dose 544 toxicity study enhanced to detect endocrine effects of hexabromocyclododecane in Wistar rats.

$545 \quad$ Toxicological Sciences 94: 281-292.

546 Wang, Y. ,2010. Developing Situation and Trend of China XPS Foam Sector. China Plastics. (in $547 \quad$ Chinese)

548 Zegers, B. N., Mets, A., Van Bommel, R., Minkenberg, C., Hamers, T., Kamstra, J.H., Pierce, G. J., 549 Boon, J. P., 2005. Levels of hexabromocyclododecane in harbor porpoises and common dolphins 550 from western European seas, with evidence for stereoisomer-specific biotransformation by $551 \quad$ cytochrome P450. Environmental Science \& Technology 39: 2095-2100.

552 
554 Gross economic costs from 2015 to 2024 (one hundred million RMB)

\begin{tabular}{|c|c|c|c|c|c|c|c|c|}
\hline & \multicolumn{3}{|c|}{ Loss of profits from sales } & \multicolumn{3}{|c|}{ Replacement costs } & \multirow{2}{*}{$\begin{array}{l}\text { managem } \\
\text { ent costs }\end{array}$} & \multirow[t]{2}{*}{ Total } \\
\hline & $\begin{array}{l}\text { Hexabromo } \\
\text { cyclododec } \\
\text { ane } \\
\text { domestic } \\
\text { sale profits }\end{array}$ & $\begin{array}{l}\text { Hexabromocy } \\
\text { clododecane } \\
\text { export } \\
\text { sale profits }\end{array}$ & $\begin{array}{l}\text { Extruded } \\
\text { polystyrene } \\
\text { foam resins } \\
\text { export sale } \\
\text { profits }\end{array}$ & $\begin{array}{l}\text { Hexabr } \\
\text { omocy } \\
\text { clodod } \\
\text { ecane }\end{array}$ & $\begin{array}{l}\text { Extrud } \\
\text { ed } \\
\text { polysty } \\
\text { rene } \\
\text { foam } \\
\text { foams }\end{array}$ & $\begin{array}{l}\text { Expan } \\
\text { dded } \\
\text { polysty } \\
\text { rene } \\
\text { foam } \\
\text { foams }\end{array}$ & & \\
\hline $\begin{array}{l}\text { 5-year } \\
\text { phase-out }\end{array}$ & 11.83 & 5.92 & 3.78 & 3.90 & 142.93 & 21.11 & 0.75 & 190.21 \\
\hline $\begin{array}{l}10 \text {-year } \\
\text { phase-out }\end{array}$ & 9.00 & 4.50 & 1.64 & 2.82 & 62.06 & 9.30 & 1.00 & 90.32 \\
\hline
\end{tabular}

556 
Table 2

558 Avoided HBCD release and potentially hazardous wastes from 2015 to 2024 (10,000 tons))

\begin{tabular}{lcc}
\hline & \multicolumn{1}{c}{$\begin{array}{c}\text { Avoided } \\
\text { Hexabromocyclododecane } \\
\text { release }\end{array}$} & $\begin{array}{c}\text { Avoided } \\
\text { hazardous wastes }\end{array}$ \\
\cline { 2 - 3 } $\begin{array}{l}\text { 5-year } \\
\text { phase-out }\end{array}$ & 0.0029 & 1468.9 \\
10-year & & 1141.5 \\
phase-out & 0.0023 & \\
\hline
\end{tabular}

559 
561 Results of the cost-effectiveness analysis

\begin{tabular}{|c|c|c|c|}
\hline & unit & 5-year phase-out & 10-year phase-out \\
\hline Total costs & billion RMB & 19.021 & 9.032 \\
\hline $\begin{array}{l}\text { Avoided Hexabromocyclododecane } \\
\text { release }\end{array}$ & ton & 29 & 23 \\
\hline Avoided potentially hazardous wastes & thousand ton & 14689 & 11415 \\
\hline Avoided workers at risk & million & 0.128 & 0.0996 \\
\hline health benefits & billion RMB & 4.033 & 3.067 \\
\hline $\begin{array}{l}\text { Net cost(considering the economic costs } \\
\text { and health benefits) }\end{array}$ & billion RMB & 14.988 & 5.365 \\
\hline Cost per unit reduction in release & billion $\mathrm{RMB} /$ ton & 0.656 & 0.393 \\
\hline $\begin{array}{l}\text { Additional cost per unit floor space of } \\
\text { completed building a }\end{array}$ & $\mathrm{RMB} / \mathrm{m}^{2}$ & 0.33 & 0.16 \\
\hline Increased housing completion cost ${ }^{\mathrm{b}}$ & $\%$ & 0.14 & 0.07 \\
\hline
\end{tabular}

$562{ }^{\mathrm{a}}$ The total floor space of buildings completed from 2015 to 2024 was predicted to be 57.7 billion $\mathrm{m}^{2}$

563 according to statistics in the China Statistics Book (2007-2013).

$564{ }^{\mathrm{b}}$ The average 2011 housing completion cost of $2373 \mathrm{RMB} / \mathrm{m}^{2}$ in China was used (CIA, 2012). 
Figure Captions

566 Fig. 1. Relationships between the floor space of completed buildings and the constant-price GDP, and 567 EPS/XPS output

568 Fig.2. The trends of variation in the outputs of HBCD and EPS foams

569 Fig.3. Proportions of industrial economic costs

570 Fig.4. Concentrations and risks of HBCD in sentiment in East China at local level in different scenarios.

571 ( numbers in brackets are the corresponding RCRs) 